\section{THE PERIODICITY AND CAUSE OF CANCER.}

By J. H. Douglas Webster. Baillière, Tindall and Cox, London. 1940. Price 12s. 6d.

The studies recorded in this book were initiated by the author's observations in the case of a patient who had recurrences of carcinoma of the breast at intervals of 33 weeks on five occasions. The object of the subject-matter is to submit evidence for the definite and to some degree predictable periodicity throughout the whole series of human neoplastic diseases, to discuss its bases and the theoretical and practical application. It is stated that periodicity probably affects about 90 per cent. of patients with neoplastic diseases and the conclusions reached are based on a study of 720 cases, and in addition 100 cases have been analysed from the records of the Stockholm Radiumhemmet. The book is divided into three chief sections, dealing with clinical, statistical and pathological and therapeutical aspects respectively. According to the author there are three types of periodicity; the first type is a period of 33 weeks; the second a half-period of approximately $16 \frac{1}{2}$ weeks; the third multiple periods of the first or second types. It is claimed that this periodicity is an intrinsic characteristic of tumour-growth. It is of interest to note that in a few patients hormonal or some other biochemical factor has been suggested in the development or regression of recurrences. The observations have been applied to the problem of therapy and it is stated that the best chance for cure is probably by irradiation at the earliest possible stage of the active phase. The periodicity principle may be an important factor to consider in connection with arranging the attendances of patients in the follow-up department. This is an interesting book containing as it does detailed studies of a new subject and we shall follow its further development.

\section{A COMPARATIVE STUDY OF THE SEASONAL INCIDENCE OF MORTALITY IN ENGLAND AND WALES AND IN THE UNITED STATES OF AMERICA.}

By E. Lewis-Faning, Med. Res. Council. Spec. Rep. Ser. No. 239. pp. 69. H.M. Stationexy Office, London. 1940. Price ls.

It is well known that the rate of mortality in England and Wales exhibits a strong seasonal trend with a maximum in the winter. In earlier times there was a second maximum in the summer, due mainly to diseases of young children, but this has been greatly reduced while the winter maximum remains and is higher than in other countries with comparable records. Dr. Lewis-Faning has made a careful comparison between English and American experience (1931-34), with particular reference to the New England States, making proper allowance for differences of age, constitution, nomenclature of causes of death, etc. Our winter mortality compares unfavourably and our summer mortality favourably with that of America, but, on balance, the advantage is with America, especially with the New England States. Our winter excess depends on diseases of the respiratory group and the American summer excess on diseases of the heart and deaths from violence. It is pointed out that most of the causes of excess depend upon diseases, which are preventable, certainly in theory, and to some extent in practice. This very careful study reinforces arguments in favour of still more study of problems of droplet infection.

\section{THE PSYCHOLOGY OF FEAR AND COURAGE.}

By Euward Glover. 128. pp. Penguin Series. 1940. Price 6d.

Dr. Glover, who has previously given us some views on the underlying psychological reaction of nations and individuals in war, now writes a small book for the layman.

This small booklet starts extremely well but rather tails off towards the end. For instance, the idea that, because we will not admit how foolish we were not to prepare for war, we attribute supernatural and uncanny powers to Hitler and his hordes, although a very ordinary psychological conception, needs bringing to the layman's mind. This is well done by comparing this conception with seven league boots and magic cloaks. This is only one example, though a good one, of how childish superstition may creep in if facts are not fairly faced.

Dr. Glover remarks rather amusingly that Mr. Churchill may sometimes turn over his money in his pocket, but we are at least certain that in a crisis he will not try to defeat the enemy by doing so.

$\mathrm{He}$ also brings out well that if you instruct a first-aid class on physical measures to deal with physical ailments, they appreciate the instruction that you offer but, if you start giving them psychological instruction on fear and how to deal with it, they immediately take exception and are offended. And yet it is a fact that one is as important as the other and that certainly from the point of view of morale the latter is infinitely more important.

This is the sort of conception with which he deals and on the whole it is a very good little book.

\section{NOTES ON THE DIAGNOSIS AND TREATMENT OF - GAS GANGRENE.}

Medical Research Council War Memorandum No. 2. H.M.S.O., London. 1940. Price 3d.

This memorandum on gas gangrene has been prepared by the War Wounds Committee of the Medical Research Council and the Committee of London Sector Pathologists. The facts leading to the diagnosis of the condition are considered in a helpful way, and stress is laid on the statement that gas gangrene is a clinical conception-the disease should not be diagnosed on bacteriological data alone. The lines of treatment to be adopted -both prophylactic and active-are described. Part of the memorandum is devoted to a suggested scheme for the bacteriological investigation of war wounds drawn up by the Committee of London Sector Pathologists. A useful publication which should be studied by those who are engaged in the treatment of casualties. 